\title{
Novel detachable stents for the treatment of benign esophageal strictures
}

\author{
LIANG SHANG $^{1 *}$, QING-SHAN PEI ${ }^{2 *}$, DAN XU ${ }^{3}$, JI-YONG LIU ${ }^{2,4}$ and JIN LIU ${ }^{2,4}$ \\ Departments of ${ }^{1}$ Gastrointestinal Surgery and ${ }^{2}$ Gastroenterology, ${ }^{3}$ Endoscopy Room, ${ }^{4}$ Laboratory of Translational Medicine, \\ Shandong Provincial Hospital Affiliated to Shandong University, Jinan, Shandong 250021, P.R. China
}

Received May 29, 2019; Accepted October 18, 2019

DOI: $10.3892 /$ etm.2019.8190

\begin{abstract}
The radial force of esophageal stents may not completely change during extraction and therefore, the procedure of stent removal may cause tissue damage. The present study reports the manufacture of 2 novel detachable stents, which were designed to reduce tissue damage through their capacity to be taken or fall apart prior to removal and evaluated the supporting properties of these stents and the extent of local mucosal injury during their removal. The stents were manufactured by braiding, heat-setting, coating and connecting. The properties of the stents were evaluated by determining the following parameters: Expansion point, softening point, stent flexibility, radial compression ratio and radial force. A total of 18 rabbits with induced esophageal stricture were randomly assigned to 3 groups as follows: Detachable stent (DS) group, biodegradable stent (BS) group and control group. The stricture rate, complications, survival, degradation and stent removal were observed over 8 weeks. The stents of the DS and BS groups provided a similar supporting effect. The stricture rate, incidence of complications and survival were also similar between the 2 groups, while significant differences were noted between the DS and control groups and between the BS and control groups. In the BS group, the stents were degraded and moved to the stomach within 7 weeks ( 2 in 6 weeks and 3 in 7 weeks). The debris was extracted using biopsy forceps. In the DS group, all stents were easy to remove and 2 cases exhibited minor hemorrhage. In conclusion, the 2 types of novel detachable stent provided an equally efficient supporting effect in vitro and in vivo and may reduce the incidence of secondary injury during stent removal.
\end{abstract}

Correspondence to: Dr Jin Liu, Department of Gastroenterology, Shandong Provincial Hospital Affiliated to Shandong University, 324 Jingwu Road, Jinan, Shandong 250021, P.R. China

E-mail: miracle713@qq.com

${ }^{*}$ Contributed equally

Key words: esophageal stricture, stents, endoscopic procedure, animal experimentation

\section{Introduction}

Benign esophageal strictures are common digestive-tract diseases and may be caused by several factors, including corrosive damage, radioactive damage and injuries following endoscopic or surgical operations (1-3). Due to recent advances in the field of endoscopic technology, the risk of esophageal stricture caused by extensive resection of esophageal mucosa following endoscopic mucosal resection or endoscopic submucosal dissection has increased to $>80 \%(4,5)$. Therefore, the prevention and treatment of benign esophageal strictures has become a matter of increasing urgency. Dilatation by balloon or Bougie dilators may not maintain long-lasting effects, resulting in the recurrence of the strictures. It has been indicated that repeated injection of steroids, a suggested treatment of strictures, may lead to steroid-associated side effects $(6,7)$. Treatments associated with cell and tissue engineering, which are still at a preliminary stage, are currently not available and require further development suggesting that their complete mechanisms of action remain to be fully elucidated (8).

At present, temporary stent placement is one of the most commonly used methods for the prevention and treatment of esophageal strictures. Luminal patency may be shaped through supporting force from the stent. However, this radial force causes tissue proliferation and re-stenosis in addition to lumen dilatation (9). Furthermore, secondary injuries to esophageal mucosa, including inflammatory reaction and fibrosis, may occur while the stent is removed from the esophagus.

At present, secondary damage during stent removal is inevitable due to the radial force of the stents. Previous studies performed by our group reported on the design of novel detachable stents $(10,11)$. The novel stents exhibit the following features: i) The stents are composed of 3 fully covered metallic meshes; ii) the metallic meshes are connected with lines and the stents may be disassembled into 3 pieces when the connecting lines are removed; iii) he design that allows for extraction of the stents without radial force is unique. In the present study, 2 subtypes of the novel detachable stent were employed. The first subtype was the detachable stent (DS) and the second was the biodegradable stent (BS; Fig. 1). In the present study, in vitro and in vivo experiments were performed to test the supporting effects and the extent of local mucosal damage when the debris of the stents was retracted. 


\section{Materials and methods}

Manufacture of stents. In the present study, the mold used for each animal $(10 \mathrm{~mm}$ in diameter and $70 \mathrm{~mm}$ in length; Shandong Medical Instrumental Institute) was manufactured as an aluminous cylinder with small bulges on its surface. The wire of the nickel-titanium memory alloy $(0.13 \mathrm{~mm}$ in diameter; Grinm Advanced Materials Co., Ltd) was braided into metallic mesh pieces on the mold and placed into a high-temperature cabinet-type electric furnace (SXL-2; Jinghong Experimental Equipment Co., Ltd) for heat-setting. The temperature range was $510-550^{\circ} \mathrm{C}$ and the heating time ranged from 15 to $35 \mathrm{~min}$. Subsequently, the metallic mesh pieces were dried with anhydrous alcohol and immersed in silicon solution for coating. The fully covered pieces were removed and dried in an oven at $120^{\circ} \mathrm{C}$ for $1 \mathrm{~h}$.

The connecting line was composed of a surgical suture line in the DS and of a poly(lactic-co-glycolic acid) (PLGA) thread (0.4-1.2 $\mathrm{mm}$ in diameter; Shandong Medical Instrumental Institute,) in the BS. The suture line was braided with a monoline chain structure pattern. The tension was adjusted by a $100 \mathrm{~g}$ balancing weight every 3 stitches. At the proximal end of the stent, a loop knot was made for stent retrieval.

Assessment of stent-supporting properties. Measurement of expansion point and softening point. The stent was immersed in a beaker containing normal saline at $0^{\circ} \mathrm{C}$ for $2 \mathrm{~min}$. External pressure was applied to deform it. When the length of the short axis in the stent was $\sim 0,50 \mathrm{ml}$ normal saline was slowly added to the beaker under constant stirring. The water temperature was recorded with an accuracy of $0.1^{\circ} \mathrm{C}$ when the sample was restored to $90 \%$ of its original shape. This critical temperature was defined as the expansion point. The softening point was defined as the temperature, which was equal to the expansion point minus $25^{\circ} \mathrm{C}$.

Measurement of stent flexibility. When the stent was bent by $30^{\circ}$, its diameter was measured by a vernier caliper with an accuracy of $0.01 \mathrm{~mm}$. The stent flexibility was calculated using the following formula: (d/D)x $100 \%$, where $d$ was the original diameter of the stent and $\mathrm{D}$ was the minimum diameter at the bending place.

Measurement of radial compression ratio. The stent was compressed to the maximum extent at a temperature range of $25-35^{\circ} \mathrm{C}$ and packed into the 'gauge' of a hard pipe ranging from $4.0-7.0 \mathrm{~mm}$ in diameter. The radial compression ratio was calculated as $r / R$ ( $r$ was the original diameter when the stent expanded and $\mathrm{R}$ was the minimum inner diameter of the 'gauge' where the stent was loaded).

Measurement of radial force. The radial force of the stent was measured with a pressure-testing machine (AGS-H; Shimadzu Corp.). The radial force was considered as the force along the stent when the short axis length of the stent was equal to half of its original diameter.

Esophageal stricture model and animal grouping. A total of $20 \mathrm{New}$ Zealand white rabbits were used for the animal experiment of stricture modeling. The present study was approved by the Ethics Committee of Shandong Provincial Hospital affiliated to Shandong University (Jinan, China; no. 2017-002). The details of the procedures were as previously described (10-12). Following fasting of the rabbits for $24 \mathrm{~h}$, they were anesthetized with 3\% sodium pentobarbital $(30 \mathrm{mg} / \mathrm{kg})$ and placed in the left lateral decubitus position. A total of $1 \mathrm{ml} 4 \%$ sodium hydroxide solution was introduced orally into each animal to produce corrosive stricture injury in the middle of the esophagus.

After 2 weeks, all of the rabbits were evaluated using a fluoroscope (Prestige; General Electric Co.). The criterion to confirm modeling success was the diameter of stricture injuries being $<1 / 2$ of the maximal diameter of the enlarged esophagus above the site of injury (Figs. 2A and 3). The success rate was $90 \%$. The rabbits with corrosive stricture were randomly assigned into 3 groups as follows: DS, BS and control groups. A total of 6 rabbits were included in each group. The rabbits of the control group did not undergo any treatment.

All animals were observed by endoscopy and fluoroscopy weekly. The animals in the BS group were observed by fluoroscopy at 1-day intervals from the end of the 4th week. The general condition and body weight of the rabbits was evaluated weekly. Complications, including stent migration, aspiration, bleeding, perforation, fistula and animal death were recorded. Rabbits that exhibited strictures of $>80 \%$ of the lumen were euthanized. Observation of the esophageal stricture was performed macroscopically (via endoscopic and fluoroscopic observation) and histologically at the end of the 8th week.

Stent placement and removal. Following anesthetization, a guidewire was inserted into the rabbit's stomach. The stent was sheathed in the delivery system and introduced using a guidewire. Subsequently, the stents were placed and expanded across the stricture injuries using fluoroscopy (Fig. 2B and C).

The connecting PLGA of the BS group was degraded and the metallic mesh pieces moved to the stomach cavity (Fig. 2D). The debris of the stents was extracted via endoscopy using biopsy forceps (FB-19K-1; Olympus Optical Co. Ltd.).

The removal operations were performed at the 8th week with an ultraslim endoscope and biopsy forceps. The details of the procedure were as follows (Fig. 4): The string of the slipknot was removed by biopsy forceps and the connecting lines were subsequently untied. The metallic mesh pieces were disassembled. As a result, the radial force of the stent was absent. Finally, the debris of the pieces was easily removed by biopsy forceps.

Hematoxylin and eosin staining $(H \& E)$. Resection of the esophagus was conducted after stent removal in order to obtain histological samples. The resected esophagi were fixed in $10 \%$ formalin overnight at room temperature. The specimens were embedded in paraffin and sliced into $5 \mu \mathrm{m}$ thick sections. H\&E staining was performed at room temperature according to routine protocols. After deparaffinization and rehydration, the slides were immersed in hematoxylin solution and then dipped in $1 \%$ acid ethanol $(1 \% \mathrm{HCl}$ in $70 \%$ ethanol) 5 times. Then the slides were rinsed with distilled water and stained with eosin solution for $3 \mathrm{~min}$. After dehydration with graded alcohol solutions and clearing with xylene, the slides were sealed by neutral balata. The slides were examined 
A
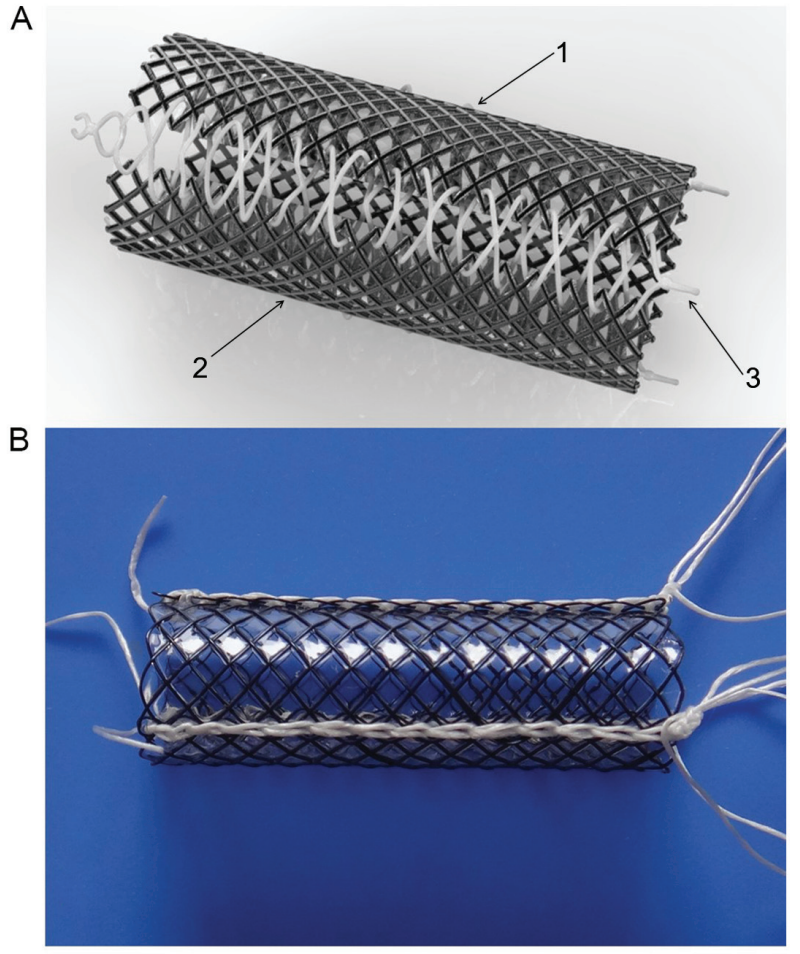

C

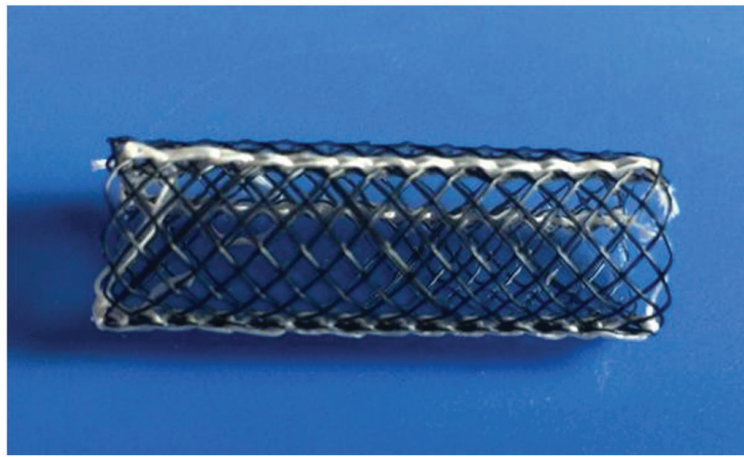

Figure 1. Images of the newly designed esophageal stent. (A) Schematic design of the stent. The major design of the stent may be disassembled into 3 pieces. (B) The novel DS was composed of 3 covered nickel-titanium meshes connected by non-absorbable surgical suture lines with slipknots. The DS may be disassembled when the slipknots are untied. (C) The novel biodegradable stent with poly(lactic-co-glycolic acid) threads as its connecting lines. DS, detachable stent.

using an Olympus BX41 fluorescence microscope (Olympus Corporation). A total of 3 sections were collected from the stricture of each rabbit and at least 2 fields of view from each were imaged.

Statistical analysis. The data were analyzed using SPSS 22.0 software (IBM Corp.). The numerical variables were compared by one-way analysis of variance. Subsequently, the least-significant differences test was applied as a post hoc test. Fisher's exact test was used to compare the categorical variables. $\mathrm{P}<0.05$ was considered to indicate a significant difference.

\section{Results}

Stent assessment. The stent diameter and length were $10 \pm 0.5$ and $30 \pm 5 \mathrm{~mm}$, respectively. The properties of the 2 types of
Table I. Properties of the two types of detachable stent.

\begin{tabular}{lcc}
\hline Property & $\begin{array}{c}\text { Biodegradable } \\
\text { stent }\end{array}$ & $\begin{array}{c}\text { Detachable } \\
\text { stent }\end{array}$ \\
\hline Softening point & $0 \pm 5^{\circ} \mathrm{C}$ & $0 \pm 5^{\circ} \mathrm{C}$ \\
Expansion point & $25 \pm 3^{\circ} \mathrm{C}$ & $25 \pm 3^{\circ} \mathrm{C}$ \\
Stent flexibility & $94 \%$ & $94 \%$ \\
Radial compression ratio & $>2.5$ & $>2.5$ \\
Radial force & $6.1 \mathrm{~N}$ & $6.1 \mathrm{~N}$ \\
\hline
\end{tabular}

stents were identical. The softening point was $0 \pm 5^{\circ} \mathrm{C}$ and the expansion point was $25 \pm 3^{\circ} \mathrm{C}$. These results indicated that the stent was able to be compressed into the stent delivery system at $\sim 0^{\circ} \mathrm{C}$ and that it was able to expand well in vivo. The stent flexibility was estimated to be $94 \%$. The radial compression ratio was $>2.5$ and the radial force was $6.1 \mathrm{~N}$. The physical properties indicated that the flexibility, radial compression ratio and radial force of the stent met the design requirements (Table I).

General condition and endoscopic examination. A total of 18 out of 20 rabbits met the criteria of the successfully established stricture model and were randomly assigned into 3 groups. Their average weight exhibited no apparent difference (Table II). The stent exhibited good expansion in the esophagus and covered the narrow part of the organ. All rabbits in the DS group survived during the observation period and no complications were observed. One animal of the BS group did not survive due to perforation. In addition, the animals in the control group did not survive due to severe stricture formation within 4 weeks.

The stents of the BS group were degraded and dropped into the stomach between weeks 6 and 7 ( 2 in 6 weeks and 3 in 7 weeks). The debris of the stent had moved to the stomach and was easily extracted using endoscopy and biopsy forceps. One rabbit did not survive due to perforation at the 4th week. Minor bleeding occurred in only one animal. Stent removal was not associated with any severe complications. In the DS group, the removal procedures were easy and smooth. A total of 2 cases exhibited minor hemorrhage. The minor bleeding did not need special treatment by endoscope and was resolved spontaneously. The stricture rate, incidence of complications, survival and stent removal exhibited no significant differences between the BS and DS groups.

Rate of stricture and histological evaluation. The rates of esophageal stricture at the time the stent was removed from the esophagus in the BS and DS groups were significantly lower than those in the control group (Table II). With this regard, no significant differences were noted between the BS and DS groups. A histological sample was taken after the removal procedure. Inflammation and the formation of granulated tissue was observed using microscopy. Tissue proliferation and development of ulcers were detected in the incised esophageal specimens. The sample of a rabbit with minor bleeding in the DS group was used for histological observation (Fig. 5). These observations indicated the presence of newly formed tissue in 
A

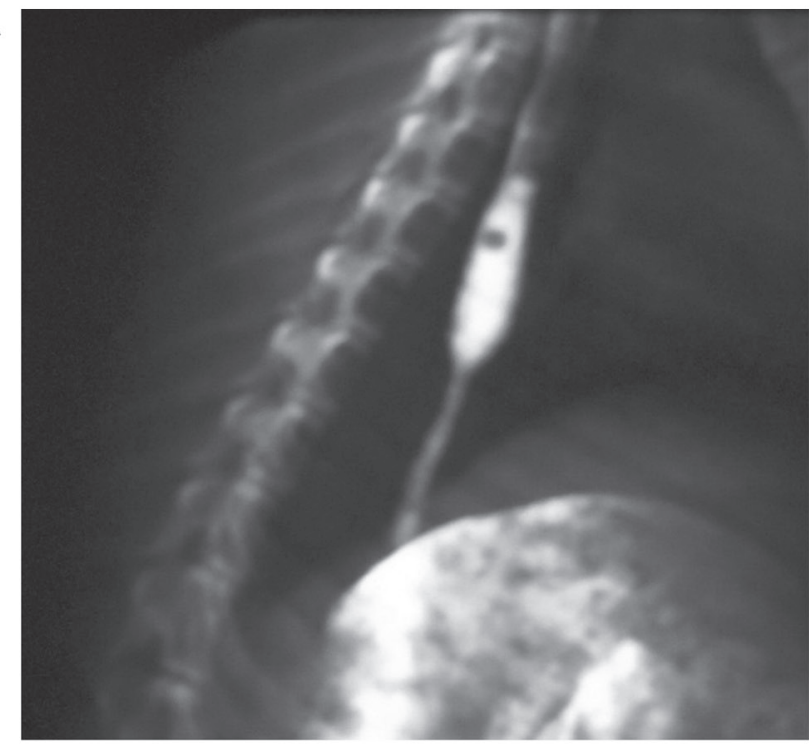

C

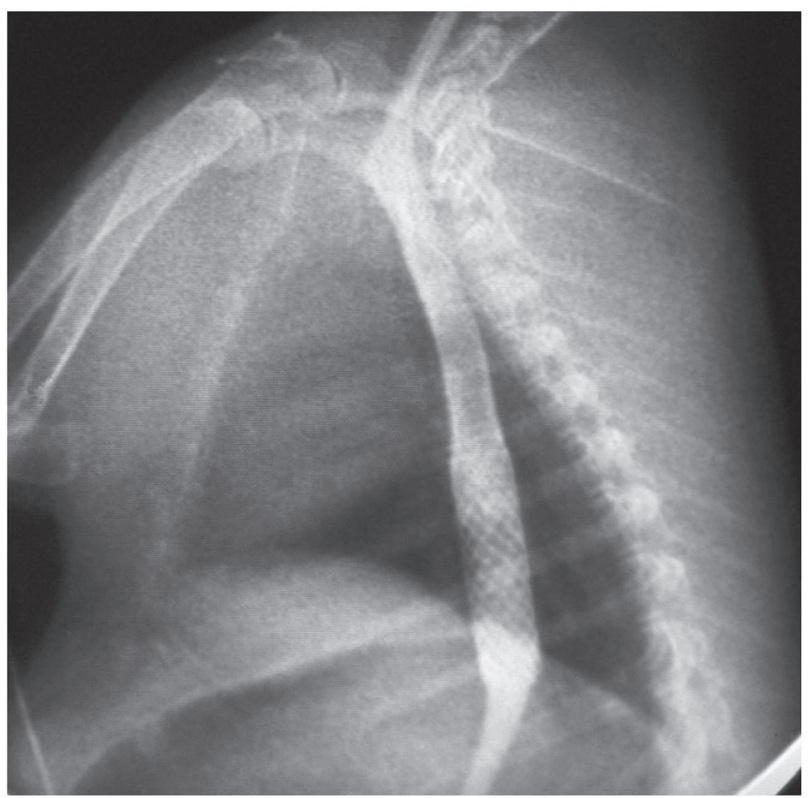

B

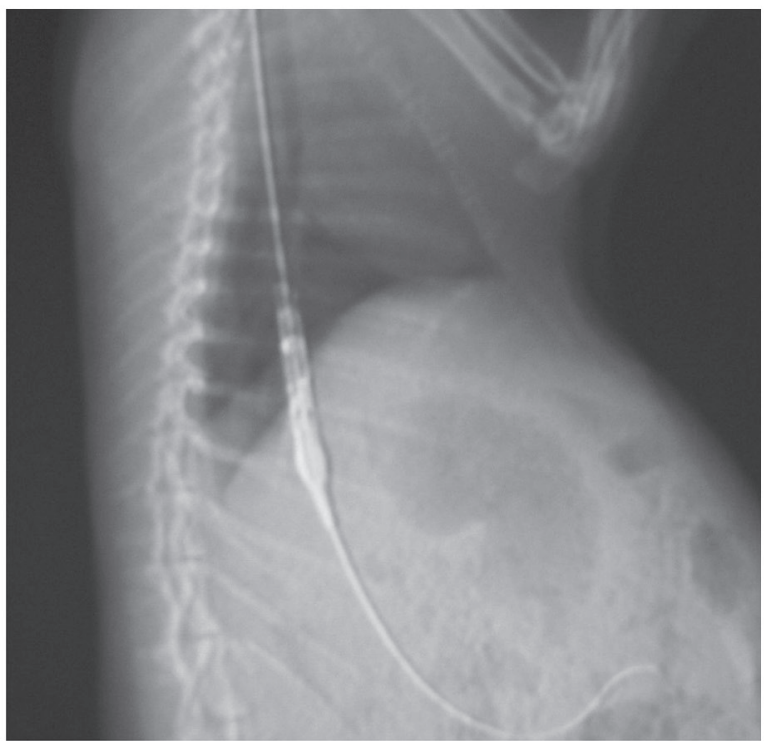

D

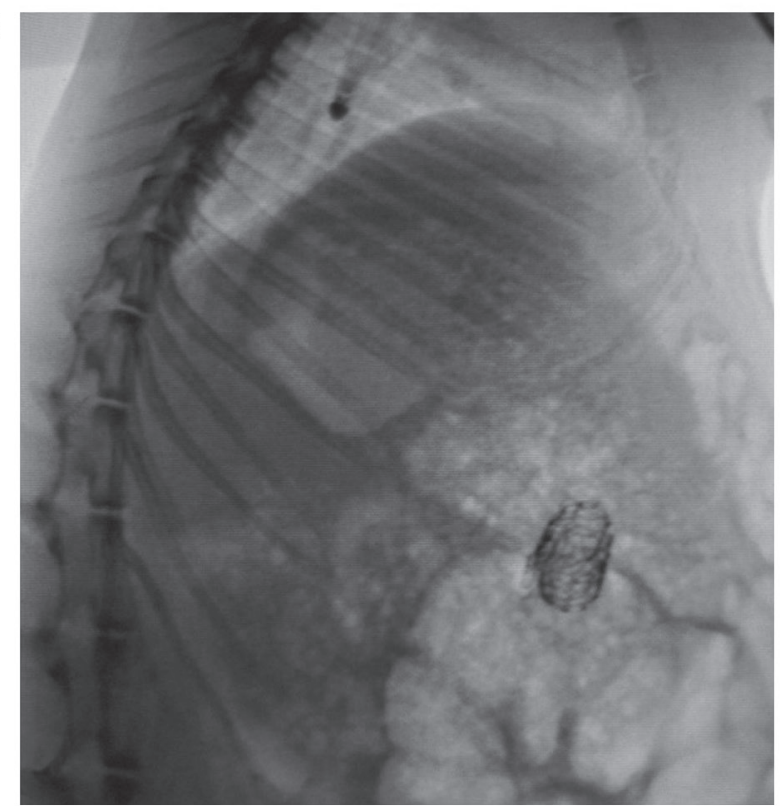

Figure 2. Fluoroscopic images of rabbits. (A) Corrosive injury had formed at 2 weeks following stricture modeling. (B) The stent was placed using a wire. (C) The stent was expanded to cover the stricture. (D) The biodegradable stent was degraded and transferred to the stomach.

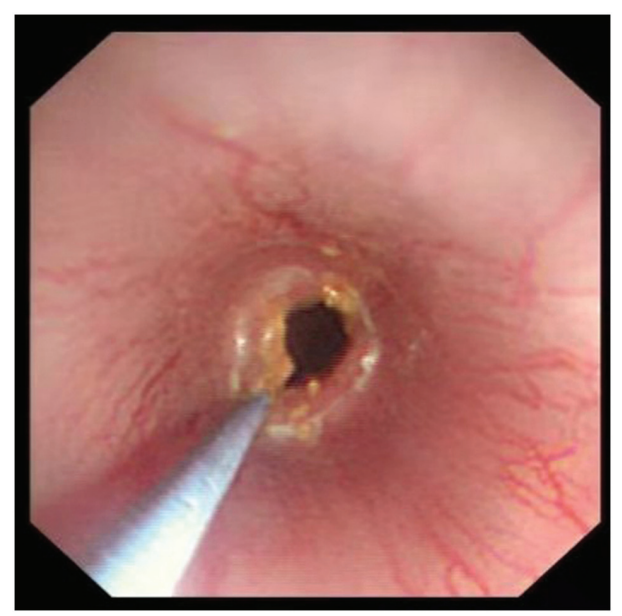

Figure 3. White-light endoscopic image of the esophageal stricture model with a guidewire as a reference. this sample. This finding suggested that the novel stents may prevent secondary damage during stent removal.

\section{Discussion}

Temporary stent implantation is considered as a viable management for the prevention and treatment of benign esophageal strictures, due to its long-lasting dilatation effect. At present, commercially available esophageal stents may be classified as self-expanding metallic stents (SEMSs), self-expanding plastic stents (SEPSs) and BS. Although uncovered SEMSs have been successfully used in palliative therapy of malignant esophageal strictures, hyperproliferation and tissue embedding on the contact surface of the meshes impede their application in benign strictures $(13,14)$. Covered SEMSs exert a strong radial force and may alleviate hyperproliferation and tissue embedding. These stents have become the most 
A

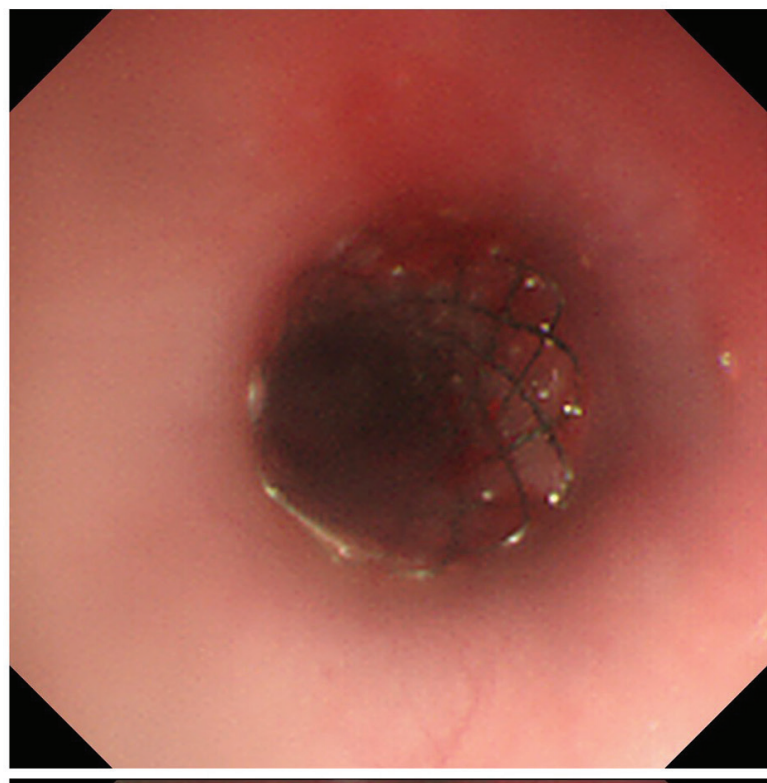

C

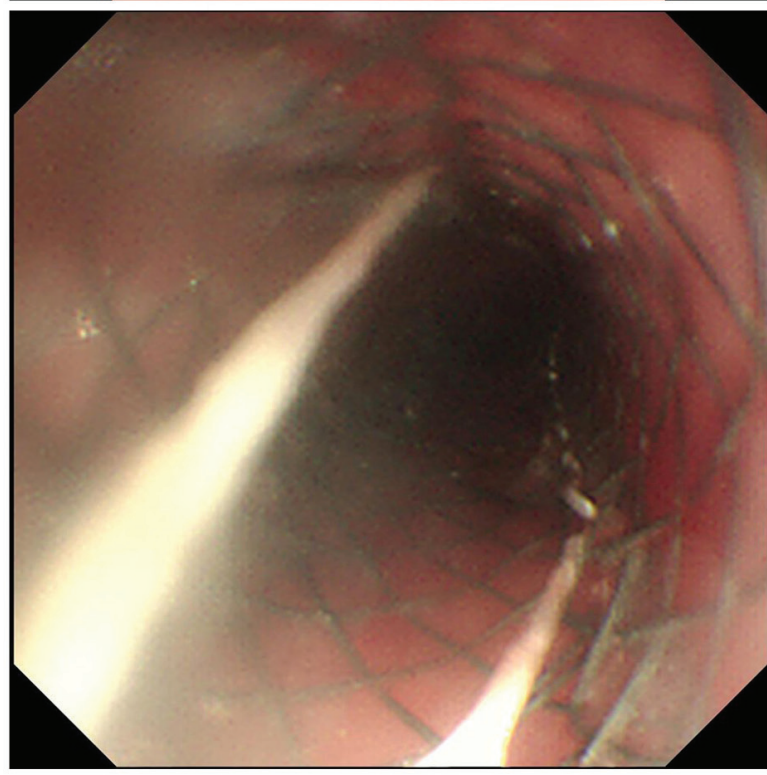

B

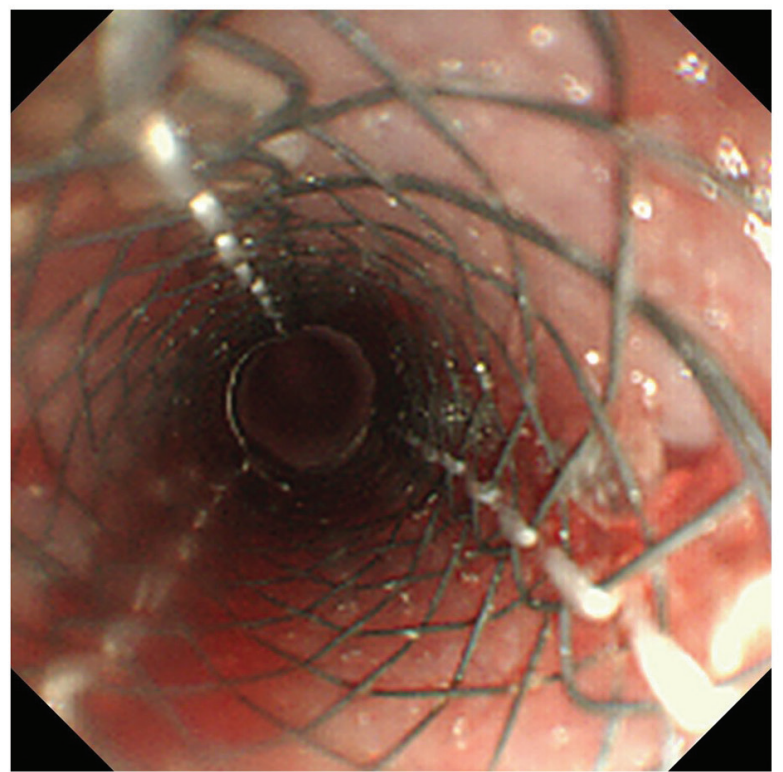

D

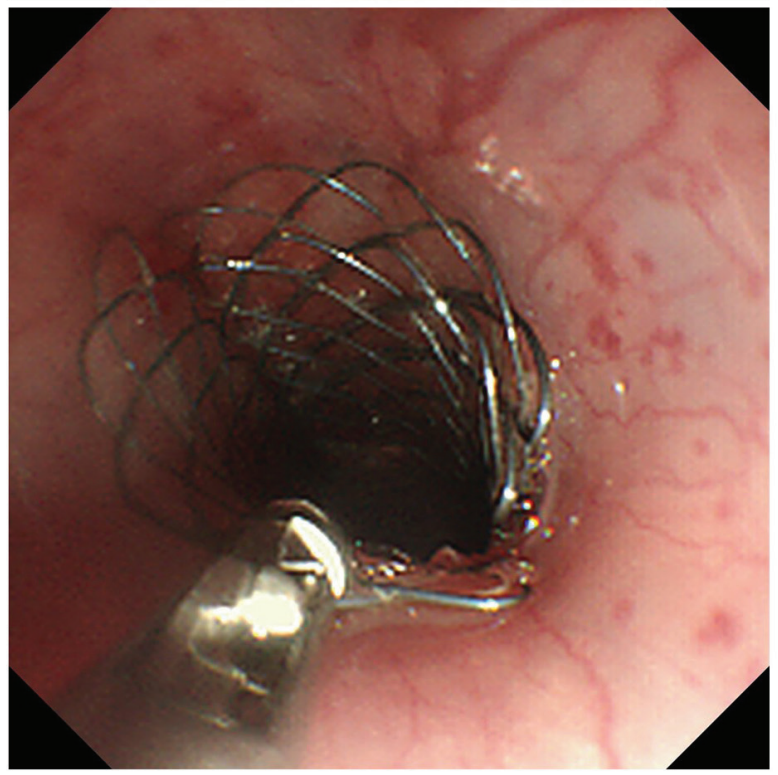

Figure 4. Images of stent extraction. (A) Observation of luminal patency on endoscopy. (B) The slipknots of the surgical suture lines were unfastened successively following removal of the string by using forceps. (C) A total of 3 pieces of nickel-titanium mesh were connected by surgical suture lines and were subsequently detached. (D) The debris of metallic meshes was removed from the esophagus.

commonly used type of stent in benign esophageal stricture. Kim et al (15) reported that the most common complication of SEMS placement was tissue in-and over-growth (31\%). The migratory rate of fully covered SEMSs ranged from 17.5 to $39 \%$ (16-18). Hyperproliferation and tissue embedding stimulated by SEPSs were less common than those stimulated by SEMSs (19). However, the migratory rate of SEPSs was generally higher than that of SEMSs. Studies have estimated that the rate of SEPS migration ranged from 7 to $85 \%$ (19-23). Removal of the migrated stents may also cause secondary damage of the mucosa due to the radial force of the stents. BS were introduced to avoid the secondary damage associated with stent removal. Satio et al (24) reported on a biodegradable esophageal stent, which was knitted from poly-l-lactic acid monofilaments in the same manner as the Ultraflex stent(Boston Scientific, MA, USA). The Ultraflex stent, which is a partially covered nitinol alloy stent knitted into a specific geometric figure is a commonly used commercially available stent in the field of esophageal stricture. The stricture was dilated prior to stent insertion and the rate of stent migration was $77 \%$. Recent studies focused on the application of Ella BD stent (Ella-SX, s.r.o., Hradec Králové, Czech Republic), which is composed of polydioxanone monofilaments (25). Tissue in-and over-growth was a common feature of the studies into the effectiveness of the Ella BD stent (Ella-CS, s.r.o., Hradec Králové, Czech Republic) and occurred due the uncovered surface of the biodegradable material (26-28). The production of a fully-covered BS has been proposed to solve this problem, although this type of material has not been previously tested (29).

Temporary stent implantation may reduce the inflammatory reaction and fibrosis during stent placement. This may be applied to avoid secondary injuries to the esophageal lumen when the stent is removed. In order to address this application, 
Table II. Characteristics of the animals used.

\begin{tabular}{|c|c|c|c|c|c|c|}
\hline Item & $\begin{array}{l}\text { Control } \\
\text { group }(n)\end{array}$ & $\begin{array}{l}\text { BS group } \\
\text { (n) }\end{array}$ & $\begin{array}{l}\text { DS group } \\
(\mathrm{n})\end{array}$ & $\begin{array}{c}\text { P-value } \\
\text { (Control vs. BS) }\end{array}$ & $\begin{array}{c}\text { P-value } \\
\text { (Control vs. DS) }\end{array}$ & $\begin{array}{c}\text { P-value } \\
\text { (BS vs. DS) }\end{array}$ \\
\hline Initial number of rabbits & 6 & 6 & 6 & - & - & \\
\hline Average weight $(\mathrm{kg})^{\mathrm{a}}$ & $2.54 \pm 0.13$ & $2.55 \pm 0.17$ & $2.56 \pm 0.17$ & 0.844 & 0.816 & 0.971 \\
\hline Stent implantation & 0 & 6 & 6 & - & - & - \\
\hline Survival & 0 & 5 & 6 & 0.015 & 0.02 & 1 \\
\hline $\begin{array}{l}\text { Degraded stent } \\
\text { Complications }\end{array}$ & - & 5 & - & - & - & - \\
\hline Proliferation & - & 1 & 0 & - & - & 0.455 \\
\hline Tissue rupture & - & 0 & 2 & - & - & 0.455 \\
\hline Minor bleeding & - & 1 & 2 & - & - & 1 \\
\hline Stent removal & - & 5 & 6 & & & 1 \\
\hline Stricture rate $(\%)^{\mathrm{b}}$ & $61.5 \pm 10.0$ & $15.0 \pm 4.1$ & $15.9 \pm 7.7$ & $<0.001$ & $<0.001$ & 0.836 \\
\hline
\end{tabular}

${ }^{\mathrm{a} A v e r a g e}$ weight was recorded 2 weeks after administration of sodium hydroxide. ${ }^{\mathrm{b}}$ Stricture rate $=[1-\mathrm{Lmax} / 50 \%(\mathrm{Lno}+\mathrm{Lna})] \mathrm{x} 100 . \mathrm{Lmax}$, diameter of the narrowest part of the esophagus; Lno, diameter of the normal mucosa on the cranial side; Lna, diameter of the normal mucosa on the caudal side; DS, detachable stent; BS, biodegradable stent.

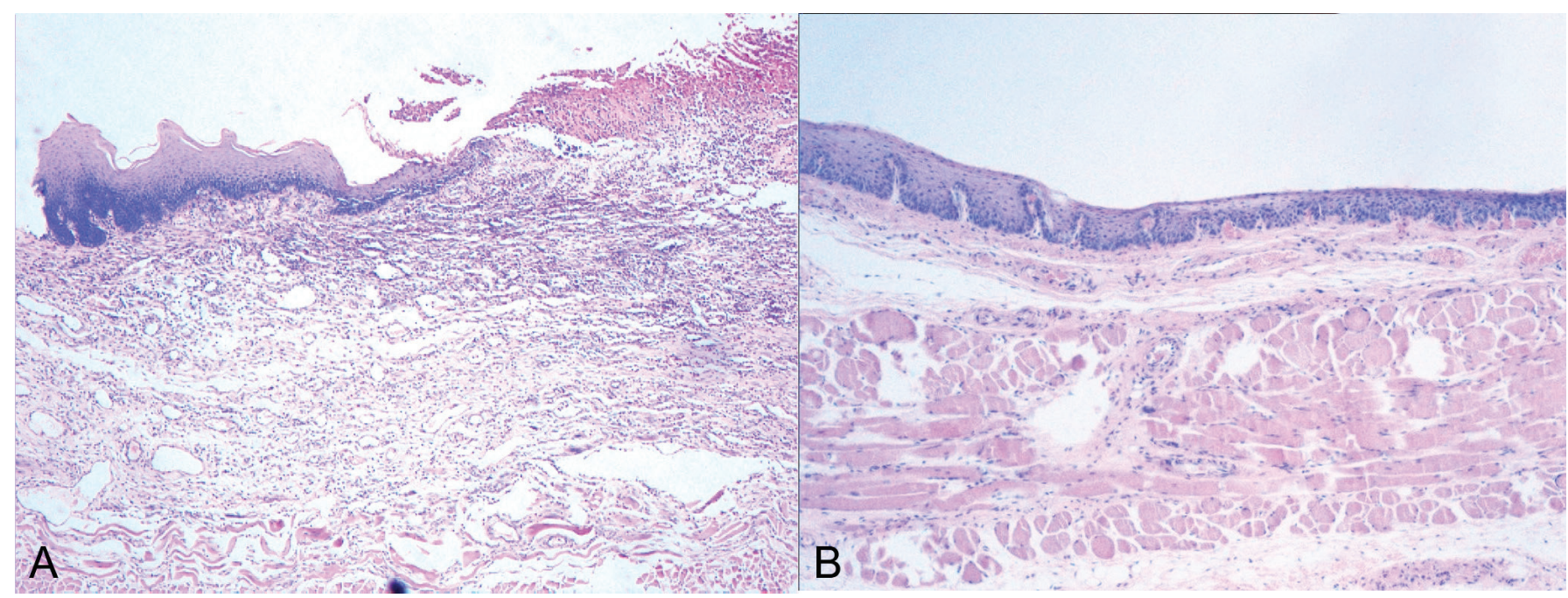

Figure 5. Histological analysis (x100; hematoxylin and eosin stain). (A) Microscopic observation indicated significant proliferation or granulation of the tissue formed following ulceration. The sample was obtained after stent retrieval and bleeding occurred prior to this. (B) An image of a control region of the esophagus for comparison.

a new series of stents was designed and developed. In the present study, the softening point of the novel DS/BS was $0 \pm 5^{\circ} \mathrm{C}$ and the expansion point was $25 \pm 3^{\circ} \mathrm{C}$. These values indicated that the stent was able to be compressed into the stent delivery system at $\sim 0^{\circ} \mathrm{C}$. Furthermore, the results demonstrated that the stent expanded well when it was inserted into the esophageal lumen. Tanaka et al (30) reported that the radial forces of commercially available esophageal stents ranged from 3.6 to $11.5 \mathrm{~N}$. The radial force of the DS was estimated to be $6.2 \mathrm{~N}$. This novel stent was comparable with the commercially available stents in providing sufficient support. In the present study, the rate of esophageal stricture in the BS and DS groups was significantly lower than that in the control group. No significant differences were noted in esophageal stricture between the BS and the DS groups. The results indicated that the novel stents may provide long-lasting dilatation effects to maintain luminal patency.
Although the radial force of the stent provides a long-lasting dilation effect, this always prevented the extraction of the stent. Stent retrieval usually caused secondary injuries of the esophageal mucosa and induced inflammatory reaction and restenosis. Eloubeidi and Lopes (31) reported that in 20 and $80 \%$ of the cases, regular and double-channel therapeutic endoscopy was adopted, respectively (18\% of the cases required assistance of one rat-tooth forceps, one rat-tooth forceps and a snare were used in $27 \%$ of cases, 2 rat-tooth forceps were used in $50 \%$ of cases and other modalities were applied in 5\% of cases). Hirdes et al (32) demonstrated the feasibility and removability of the 'stent-in-stent' technique. The authors used a fully-covered stent of the same or slightly larger size. The stent was inserted into the initially placed embedded stent and the 2 stents were removed simultaneously when the pressure resulted in necrosis of the overgrowth tissue 
at 10-14 days following placement. In the present study, a single-channel ultraslim endoscope and biopsy forceps were used for stent removal.

In the DS group, the process of stent removal was smooth and easy. The radial force of the DS was eliminated by removing the string of the thread. The connecting threads were pulled out of the stent, resulting in its collapse. The metallic pieces were removed successively. A total of 2 rabbits were selected for further study following stent retrieval as these two rabbits exhibited minor bleeding during stent removal. The animals exhibited severe inflammation of the esophagus and ulcer formation with the presence of minor bleeding. Inflammation may cause bleeding during stent retrieval. Proliferation or granulation of the tissue and ulceration are common in tissues after stent implantation. As a result, when the stent is pulled free from the esophagus, the contact surface of the stent and blunt traction can severely damage the esophageal tissue where new tissue or a pressure ulcer has formed. In the 2 cases, the minor bleeding did not need special treatment by endoscope and resolved spontaneously. This illustrated that the novel DS may be used to avoid severe secondary injury during stent removal.

In the BS group, the stents were degraded and transferred to the stomach between weeks 6 and 7. Only one rabbit did not survive. The debris of the stent was transferred to the stomach and was easily extracted using biopsy forceps and endoscopy. Minor bleeding occurred in one case, though in the absence of severe complications associated with stent removal. At present, this novel BS is the only fully-covered stent, which may in part be biodegraded. Euthanasia and separation of esophagus were conducted to obtain histological specimens of rabbit tissue. This tissue showed clear proliferation or granulation following ulceration when compared with normal tissue. Severe inflammation may cause tissue vulnerability. When the pieces of the stent were removed from the esophagus, secondary damage, such as bleeding and tissue rupture, inevitably occurred due to friction between the surface of the stent pieces and the inflamed esophageal mucosa. In the absence of the radial force of the stent, the bleeding associated with stent removal was minor. This result suggested that the newly designed detachable stents may avoid secondary damage during stent removal procedure.

The limitations of the present study were the lack of additional in vitro and clinical data to support the in vivo results. Large patient studies are required to collect additional data regarding the efficacy of DS/BS used for the treatment of benign esophageal strictures. Further studies should focus on different shapes of stent, which may be used to treat different types of disease in the digestive tract.

In conclusion, the present study indicated that the novel DS/BS for the treatment of esophageal stricture was safe and easily placed. This novel type of stent may offer long-lasting supporting effects and avoid secondary injuries to the esophageal lumen during stent removal.

\section{Acknowledgements}

The authors would like to thank Mr. Dong Wang and Mr. Junqi Li from the Institute of Shandong Provincial Medical Instruments (Jinan, China) for their technical support.

\section{Funding}

The present study was supported by a grant from the Natural Science Foundation of Shandong Province, China (grant no. ZR201702230130).

\section{Availability of data and materials}

The datasets used and/or analyzed during the current study are available from the corresponding author on reasonable request.

\section{Authors' contributions}

LS performed the study, analyzed and interpreted the data and drafted the manuscript. QSP participated in the animal experiments and in the endoscopic operation. DX assisted with the endoscopic operation and analyzed the data. JYL provided technical support and participated in the endoscopic operation. JL participated in the experimental design and supervised the study. All authors read and approved the final version of the manuscript.

\section{Ethics approval and consent to participate}

The present study was approved by the Ethics Committee of Shandong Provincial Hospital affiliated to Shandong University (Jinan, China; no. 2017-002).

\section{Patient consent for publication}

Not applicable

\section{Competing interests}

JYL and JL own the patent for the detachable stents (patent no. ZL2011-10323099.5, 2011). The remaining authors have no competing interests.

\section{References}

1. Hasan M and Maple JT: Traversing difficult esophageal strictures from the retrograde apprpach. Tech Gastrointest Endosc 10: 149-154, 2008.

2. Shah JN: Benign refractory esophageal strictures: Widening the endoscopist's role. Gastrointest Endosc 63: 164-167, 2006.

3. Luchtefeld MA, Milsom JW, Senagore A, Surrell JA and Mazier WP: Colorectal anastomotic stenosis: Results of a survey of the ASCRS membership. Dis Colon Rectum 32: 733-736, 1989.

4. Mori H, Rafiq K, Kobara H, Fujihara S, Nishiyama N, Oryuu M, Suzuki Y and Masaki T: Steroid permeation into the artificial ulcer by combined steroid gel application and balloon dilatation: Prevention of esophageal stricture. J Gastroenterol Hepatol 28: 999-1003, 2013.

5. Isomoto H, Yamaguchi N, Nakayama T, Hayashi T, Nishiyama $H$, Ohnita K, Takeshima F, Shikuwa S, Kohno S and Nakao K: Management of esophageal stricture after complete circular endoscopic submucosal dissection for superficial esophageal squamous cell carcinoma. BMC Gastroenterol 11: 46, 2011.

6. Kobayashi S, Kanai N, Ohki S, Takagi R, Yamaguchi N, Isomoto H, Kasai Y, Hosoi T, Nakao K, Eguchi S, et al: Prevention of esophageal strictures after endoscopic submucosal dissection. World J Gastroenterol 20: 15098-15109, 2014

7. Yamashina T, Uedo N, Fujii M, Ishihara R, Mikamori M, Motoori M, Yano $\mathrm{M}$ and Iishi $\mathrm{H}$ : Delayed perforation after intralesional triamcinolone injection for esophageal stricture following endoscopic submucosal dissection. Endoscopy 45 (Suppl 2) UCTN: E92, 2013. 
8. Tang J, Ye S, Ji X, Liu F and Li Z: Deployment of carboxymethyl cellulose sheets to prevent esophageal stricture after full circumferential endoscopic submucosal dissection: A porcine model. Dig Endosc 30: 608-615, 2018.

9. Park JH, Song HY, Park JY Kim JH, Kim YH, Kim JH and Kim SB: Temporary stent placement with concurrent chemoradiation therapy in patients with unresectable oesophageal carcinoma: Is there an optimal time for stent removal? Eur Radiol 23: 1940-1945, 2013.

10. Liu J, Shang L, Liu JY and Qin CY: Newly designed 'pieced' stent in a rabbit model of benign esophageal stricture. World J Gastroenterol 21: 8629-8635, 2015.

11. Liu J, Shang L, Liu J and Qin C: A novel biodegradable esophageal stent: Results from mechanical and animal experiments. Am J Transl Res 8: 1108-1114, 2016.

12. Thompson JN: Corrosive esophageal injuries.II. An investigation of treatment methods and histochemical analysis of esophagea strictures in a new animal model. Laryngoscope 97: 1191-1202, 1987.

13. Kozarek RA: Expandable endoprostheses for gastrointestinal stenoses. Gastrointest Endosc Clin North Am 4: 279-295, 1994.

14. Tan BS, Kennedy C, Morgan R, Owen W and Adam A: Using uncovered metallic endoprostheses to treat recurrent benign esophageal strictures. AJR Am J Roentgenol 169: 1281-1284, 1997.

15. Kim JH, Song HY, Choi EK, Kim KR, Shin JH and Lim JO: Temporary metallic stent placement in the treatment of refractory benign esophageal strictures: Results and factors associated with outcome in 55 patients. Eur Radiol 19: 384-390, 2009.

16. Senousy BE, Gupte AR, Draganov PV, Forsmark CE and Wagh MS: Fully covered Alimaxx esophageal metal stents in the endoscopic treatment of benign esophageal diseases. Dig Dis Sci 55: 3399-3403, 2010.

17. EI Hajj II, Imperiale TF, Rex DK, Ballard D, Kesler KA, Birdas TJ, Fatima H, Kessler WR and DeWitt JM: Treatment of esophageal leaks, fistulae, and perforations with temporary stents: Evaluation of efficacy, adverse events, and factors associated with successful outcomes. Gastrointest Endosc 79: 589-598, 2014.

18. Wilson JL, Louie BE, Farivar AS, Vallières E and Aye RW: Fully covered self-expanding metal stents are effective for benign esophagogatric disruptions and strictures. J Gastrointest Surg 17: 2045-2050, 2013.

19. Dua KS, Vleggaar FP, Santharam R and Siersema PD: Removable self-expanding plastic esophageal stent as a continuous, non-permanent dilator in treating refractory benign esophageal strictures: A prospective two-center study. Am J Gastroenterol 103: 2988-2994, 2008.

20. Oh YS, Kochman ML, Ahmad NA and Ginsberg GG: Clinical outcomes after self-expanding plastic stent placement for refractory benign esophageal strictures. Dig Dis Sci 55: 1344-1348, 2010.

21. Repici A, Conio M, De Angelis C, Battaglia E, Musso A, Pellicano R, Goss M, Venezia G, Rizzetto M and Saracco G: Temporary placement of an expandable polyester silicone-covered stent for treatmet of refractory benign esophageal stricture. Gastrointest Endosc 60: 513-519, 2004.
22. Triester SL, Fleischer DE and Sharma VK: Failure of self-expanding plastic stents in treatment of refractory benign esopohageal strictures. Endoscopy 38: 533-537, 2006.

23. Barthel JS, Kelley ST and Klapman JB: Management of persistent gastroesophageal anastomotic strictures with removalbe self-expandable polyester silicon-covered(Pollyflex) stents: An alternative to serial dilation. Gastrointest Endosc 67: 546-552, 2008.

24. Saito Y, Tanaka T, Andoh A, Minematsu H, Hata K, Tsujikawa T, Nitta N, Murata K and Fujiyama Y: Novel biodegradable stents for benign esophageal strictures following endoscopic submucosal dissection. Dig Dis Sci 53: 330-333, 2008.

25. van Boeckel PG, Vleggaar FP and Siersema PD: Biodegradable stent placement in the esophagus. Expert Rev Med Devices 10: 37-43, 2013.

26. Dumoulin FL and Plassmann D: Tissue hyperplasia following placement of biodegradable stent for a refractory esophageal stricture: Treatment with argon plasm coagulation. Endoscopy 44 (Suppl 2) UCTN: E356-E357, 2012.

27. Hair CS and Devonshire DA: Severe hyperplastic tissue stenosis of a novel biodegradable esophageal stent and subsequent successful management with high-pressure balloon dilation. Endoscopy 42 (Suppl 2): E132-E133, 2010.

28. van Hooft JE, van Berge Henegouwen MI, Rauws EA, Bergman JJ, Busch OR and Fockens P: Endoscopic treatment of benign anastomotic esophagogastric strictures with a biodegradable stent. Gastrointest Endosc 73: 1043-1047, 2011.

29. van Boeckel PG, Vleggaar FP and Siersema PD: A comparison of temporary self-expanding plastic and biodegradable stents for refractory benign esophageal strictures. Clin Gastroenterol Heppatol 9: 653-659, 2011.

30. Tanaka T, Takahashi M, Nitta N, Furukawa A, Andoh A, Saito Y, Fujiyama Y and Murata K: Newly developed biodegradable stents for benign gastrointestinal tract stenoses: A preliminary clinical trial. Digestion 74: 199-205, 2006

31. Eloubeidi MA and Lopes TL: Novel removable internally fully covered self-expanding metal esophageal stent: Feasibility, technique of removal, and tissue response in humans. Am J Gastroenterol 104: 1374-1381, 2009.

32. Hirdes MM, Siersema PH, Houben MH, Weusten BL and Vleggaar FP: Stent-in-stent technique for removal of embedded esophageal self-expanding metal stents. Am J Gastroenterol 106: 286-293, 2011. 